\title{
Multipl Skleroz Hastasında Gelişen Narkolepsi Sendromu
}

\section{Narcolepsy Syndrome in a Patient with Multiple Sclerosis}

\author{
Deniz Yerdelen, Gülçin Benbir*, Uğur Uygunoğlu*, Aksel Siva*, Derya Karadeniz* \\ Başkent Üniversitesi Tıp Fakültesi, Nöroloji Anabilim Dalı, Adana, Türkiye \\ *Istanbul Üniversitesi Cerrahpaşa Tıp Fakültesi, Nöroloji Anabilim Dalı, Istanbul, Türkiye
}

\section{Özet}

Narkolepsi sendromu katapleksinin eşlik ettiği ya da etmediği, aşırı gündüz uykululuk ile şekillenen bir hastalıktır. Gündüz aşırı uykululuk ve katapleksiye ek olarak bozulmuş gece uykusu, uyku paralizisi, hipnopompik/hipnagojik halüsinasyonlar gibi REM uyku evresine ait bulgular eşlik edebilmektedir. Idiyopatik narkolepsi sendromunun patofizyolojisinde, otoimmun bir sürecin neden olduğu düşünülen hipokretin (oreksin) üreten hipotalamik nöronların kaybı gösterilmiştir. Ender olmakla birlikte, narkolepsi sendromu, diğer medikal hastalıklara bağlı olarak da görülebilmektedir. Bu olgu sunumunda, uzun yıllardır multipl skleroz (MS) tanısı ile takip edilirken narkolepsi sendromu gelişen 37 yaşındaki bir kadın hasta bağlamında MS ve narkolepsi birlikteliğine dikkati çekmeyi amaçladık; hipotalamik lezyonlar ile akut MS atağı narkolepsi şeklinde kendini gösterebileceği gibi, MS aktif değilken dahi ortak immün mekanizmalar üzerinden narkolepsi için yatkınlık oluşturabileceği bilinmelidir. (JTSM 2014;2:58-9)

Anahtar Kelimeler: Narkolepsi sendromu, multipl skleroz, hipotalamik lezyonlar, immün mekanizmalar

\begin{abstract}
Summary
Narcolepsy syndrome is characterized by excessive daytime sleepiness with or without cataplexy. In addition to excessive daytime sleepiness and cataplexy, other symptoms related to REM-sleep such as disturbed night sleep, sleep paralysis and hypnopompic/hypnagogic hallucinations may accompany. In the pathophysiology of idiopathic narcolepsy syndrome, loss of hypothalamic neurons producing hypocretin (orexin) has been shown, probably secondary to an autoimmune process. Although uncommon, narcolepsy syndrome may occur secondary to other neurological disorders. In this case report, a 37-year-old female patient followed due to multiple sclerosis (MS), who developed narcolepsy syndrome is presented; on this context, we aimed to draw attention to association of MS and narcolepsy syndrome. An acute MS attack may present as narcolepsy syndrome due to hypothalamic lesions, or even when MS is not active, these patients are susceptible to develop narcolepsy syndrome probably due to shared autoimmune mechanisms. (JTSM 2014;2:58-9)
\end{abstract}

Key Words: Narcolepsy syndrome, multiple sclerosis, hypothalamic lesions, autoimmune mechanisms

\section{Giriş}

Narkolepsi sendromu katapleksinin eşlik ettiği ya da etmediği, aşırı gündüz uykululuk ile şekillenen bir hastalıktır. Gündüz aşırı uykululuk ve katapleksiye ek olarak bozulmuş gece uykusu, uyku paralizisi, hipnopompik/hipnagojik halüsinasyonlar gibi REM uyku evresine ait bulgular eşlik edebilmektedir. Gündüz uyku ataklarının süresi çoğunlukla birkaç saniye ile birkaç dakika arasında değişir, ataklar kısa süreli olmasına karşın oldukça dinlendiricidir. Gündüz uyku ataklarının yemek yeme veya araba kullanma gibi uygun olmayan ortamlarda ortaya çıkması da tipiktir $(1,2)$.

Farklı ülke ve etnik gruplarda yapılan çalışmalarda narkolepsi sendromunun toplumların \%0,03'ünü etkilediği gösterilmiştir $(1,2)$. İdiyopatik narkolepsi sendromunun patofizyolojisinde, otoimmun bir sürecin neden olduğu düşünülen hipokretin (oreksin) üreten hipotalamik nöronların kaybı gösterilmiştir (3). Özellikle katapleksinin eşlik ettiği narkolepsi sendromunun HLA DR2/DQB1*0602 ile birlikteliği etiyolojisindeki otoimmün hipotezi desteklemektedir (4). Ender olmakla birlikte, narkolepsi sendromu, diğer medikal hastalıklara bağlı olarak da görülebilmektedir. Sekonder narkolepsi sendromu etiyolojileri arasında ensefalit, kafa travması, intrakraniyal tümör veya multipl skleroz (MS) ve optik nöromiyelit gibi enflamatuar hastalıklar yer almaktadır $(3,5)$. Burada, uzun yıllardır multipl skleroz tanısı ile takip edilirken narkolepsi sendromu gelişen 37 yaşındaki bir kadın hasta sunulmaktadır.

\section{Olgu}

Otuz yedi yaşında kadın hasta, gündüz aşııı uykululuk şikayeti ile uyku polikliniğimize başvurdu. Hasta son 1,5 yıl önce ani olarak başlayan, günde birkaç kez ortaya çıkan ve en fazla 5 dakika süren engel olamadığı uyku atakları tarif ediyor. Uyku atakları esnasında rüya görüyor ve dinlenmiş olarak uyanıyor. Hasta katapleksi atağı tarif etmiyor. Gece uykularının ise oldukça sık bölündüğünü ifade ediyor. Yaklaşık birkaç aydır, ayda bir sıklığında ortaya çıkan, uykudan uyanma esnasında (hipnopompik) görsel halüsinasyonlar ve kabus atakları tarif ediyor. 
Özgeçmişinde hastanın 22 yaşından beri multipl skleroz tanısı ile takip edildiği ve yaklaşık 20 yıldır interferon tedavisi altında olduğu öğrenildi. Hastanın son 5 yıldır kullandığı tedavi şeması haftada 3 kez interferon beta- 1-alfa 44 mcg (SC) şeklinde idi; bu tedavi altında yeni atak geliş̧mediği öğrenildi. Hastanın EDSS (Expanded Disability Status Scale) skoru 1.0 olarak saptandı (sağ vücut yarısında hafif parezi ve vizyon kaybı). Hastanın son 1 ayda $10 \mathrm{~kg}$ aldığı öğrenildi. Eski sigara kullanıcısı olan hastanın mevcut sigara veya alkol tüketimi yoktu. Aile hikayesinde özellik yoktu.

Sübjektif gündüz aşırı uykululuk testi olan Epworth Uykululuk Skalası 20 puan ile aşırı uykululuk halini göstermekte idi. Subjektif gece uyku kalitesini değerlendiren Pittsburg uyku kalitesi testi ise 9 puan ile gece kötü uyku kalitesini yansıtmakta idi. Objektif uyku kalitesi tüm gece polisomnografisi (PSG) ile değerlendirildi. Patolojik düzeyde anormal solunum olayı ya da periyodik bacak hareketi izlenmedi. Çene elektromiyografi kayıtlarında REM uyku evresinde zaman zaman tonik ve fazik aktivite artışları dikkati çekti, ancak buna eşlik eden verbal ve/ veya motor aktivite görülmedi. Objektif gündüz aşırı uykululuk hali Çoklu Uyku Latans Testi (ÇULT) ile değerlendirildi; 4 kez tekrarlanan kısa süreli gündüz uyku testinde ortalama uyku latansı 1,5 dakika idi ve 3 testte uykunun REM uyku evresi ile başladığı izlendi. Hastaya Narkolepsi sendromu tanısı konularak modafinil (200 mg/gün) tedavisi başlandı ve hastanın gündüz aşırı uykululuk şikayeti tamamen kontrol altına alındı. Narkolepsi sendromuna eşlik eden hipnopompik halüsinasyonlar ve kabus atakları nadir olduğu için ek tedavi önerilmedi.

Hastanın gerek eski gerekse yeni gelişen aşırı gündüz uykululuk tablosu sonrası tekrarlanan manyetik rezonans incelemeleri (MRi), MS konusunda uzman nörolog ve nöroradyologlar tarafından değerlendirildi; MS için tipik olan periventriküler, subkortikal ve serebellar demiyelinizan lezyonlar haricinde (Şekil 1), hipotalamik bölgede bir lezyon olmadığı görüldü.

\section{Tartışma}

Multipl skleroz hastalarında kötü uyku kalitesi ve yorgunluk (fatigue) oldukça sık karşılaşılan uyku bozukluklarıdır (6-8). Oldukça nadir olarak görülmekle birlikte, multipl skleroz, sekonder narkolepsi sendromu etiyolojileri arasında da yer almaktadır (9). Multipl skleroz plaklarının hipotalamik bölgeyi

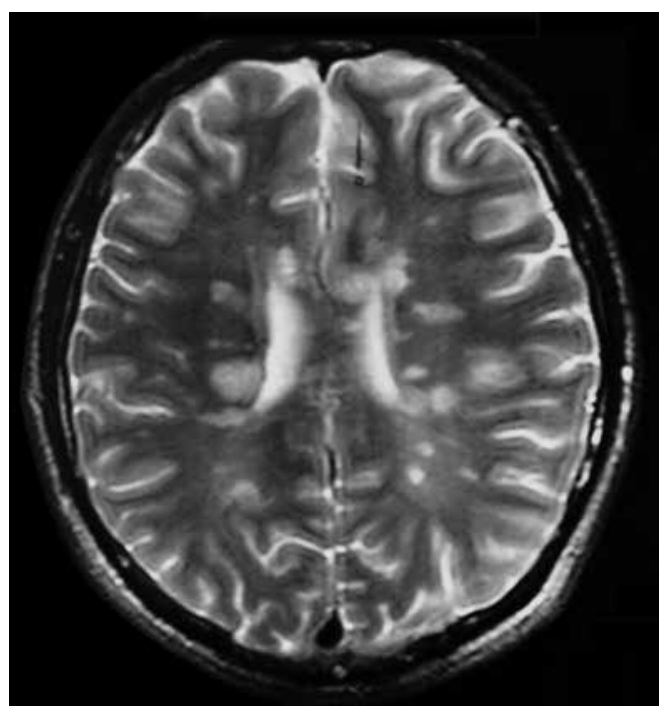

Şekil 1. MS hastasının MR görüntüleri etkilemesi sonucu narkolepsi sendromu ortaya çıkabilir. Ancak öne sürülen bir diğer mekanizma, her iki bozukluğun da HLA DR2 ile ilişkili olması nedeniyle, multipl skleroz ve narkolepsi sendromunun ortak bir otoimmün mekanizma sonucu ortaya çıktığı şeklindedir $(10,11)$. Bizim hastamızda hipotalamik lezyonların olmaması da bu iki hastalıktaki ortak otoimmün mekanizmayı desteklemektedir.

MS hastalarındaki narkoleptik şikayetlerin tedavi kılavuzu, primer narkolepsi sendromuna benzer şekildedir. Ancak hipotalamik lezyonların varlığında yüksek doz metilprednizolon narkolepsi şikayetlerinin giderilmesinde tek başına faydalı olabilir (12). Farmakolojik olmayan yaklaşımlar arasında danışmanlık hizmetleri ve yaşam biçimi değişiklikleri yer alır (13). Narkolepsiye özgü tedaviler ise, uyanıklığı sürdürmeye yarayan modafinil, metilfenidat veya sodyum oksibat gibi uyarıcı ajanlar ile REM uykusunu inhibe eden ve katapleksi, halüsinasyonlar ya da uyku paralizisi gibi diğer eşlik eden şikayetlerin giderilmesinde kullanılan antidepresan ajanları içermektedir $(13,14)$. Bu olgu sunumunda, MS ve narkolepsi birlikteliğine dikkati çekmeyi amaçladık; hipotalamik lezyonlar ile akut MS atağı narkolepsi şeklinde kendini gösterebileceği gibi, MS aktif değilken dahi ortak immün mekanizmalar üzerinden narkolepsi için yatkınlık oluşturabileceği bilinmelidir.

\section{Kaynaklar}

1. Thorpy MJ. Cataplexy associated with narcolepsy: epidemiology, pathophysiology and management. CNS Drugs 2006;20:43-50.

2. Öztura I. Narkolepsi. Kaynak $H$, Ardıç S, editörler. Uyku fizyolojisi ve hastalıkları. Nobel Tıp Kitabevi; 2011; s. 309-15.

3. Thannickal TC, Moore RY, Nienhuis R, Ramanathan L, Gulyani S, Aldrich $\mathrm{M}$, et al. Reduced number of hypocretin neurons in human narcolepsy. Neuron 2000;27:469-74.

4. Nishino S. Clinical and neurobiological aspects of narcolepsy. Sleep Med 2007;8:373-99.

5. Nishino S, Kanbayashi T. Symptomatic narcolepsy, cataplexy and hypersomnia, and their implications in the hypothalamic hypocretin/ orexin system. Sleep Med Rev 2005;9:269-310.

6. Kaynak H, Altintaş A, Kaynak D, Uyanik O, Saip S, Ağaoğlu J, et al. Fatigue and sleep disturbance in multiple sclerosis. Eur J Neurol 2006;13:1333-9.

7. Bamer AM, Johnson KL, Amtmann D, Kraft GH. Prevalence of sleep problems in individuals with multiple sclerosis. Mult Scler 2008; 14:1127-30.

8. Merlino G, Fratticil L, Lenchig $C$, Valente $M$, Cargnelutti D, Picello $M$, et al. Prevalence of 'poor sleep' among patients with multiple sclerosis: an independent predictor of mental and physical status. Sleep Med 2009; 10:26-34.

9. Lunde HM, Bjorvatn B, Myhr KM, Bø L. Clinical assessment and management of sleep disorders in multiple sclerosis: a literature review. Acta Neurol Scand Suppl 2013;196:24-30.

10. Wang CY, Kawashima H, Takami T, Yamada N, Miyajima T, Ogihara M, et al. A case of multiple sclerosis with initial symptoms of narcolepsy. No To Hattatsu 1998;30:300-6.

11. Kanbayashi T, Shimohata T, Nakashima I, Yaguchi H, Yabe I, Nishizawa M, et al. Symptomatic Narcolepsy in Patients With Neuromyelitis Optica and Multiple Sclerosis: new neurochemical and immunological implications. Arch Neurol 2009;66:1563-6.

12. Brass SD, Duquette P, Proulx-Therrien J, Auerbach S. Sleep disorders in patients with multiple sclerosis. Sleep Med Rev 2010;14:121-9.

13. Nishino S, Okuro M. Emerging treatments for narcolepsy and its related disorders. Expert Opin Emerg Drugs 2010;15:139-58.

14. Billiard M, Bassetti C, Dauvilliers Y, Dolenc-Groselj L, Lammers G], Mayer $G$, et al. EFNS guidelines on management of narcolepsy. Eur ] Neurol 2006;13:1035-48. 